\title{
Differential efficiency in exogenous DNA acquisition among closely related Salmonella strains: implications in bacterial speciation
}

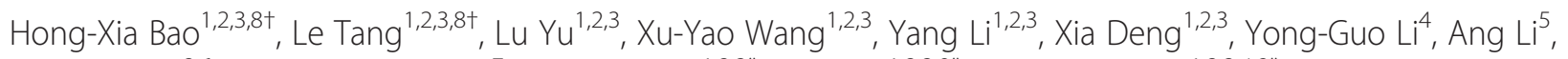
Da-Ling Zhu ${ }^{2,6}$, Randal N Johnston ${ }^{7}$, Gui-Rong Liu ${ }^{1,2,3^{*}}$, Ye Feng ${ }^{1,2,3,9^{*}}$ and Shu-Lin Liu ${ }^{1,2,3,4,8^{*}}$

\begin{abstract}
Background: Acquisition of exogenous genetic material is a key event in bacterial speciation. It seems reasonable to assume that recombination of the incoming DNA into genome would be more efficient with higher levels of relatedness between the DNA donor and recipient. If so, bacterial speciation would be a smooth process, leading to a continuous spectrum of genomic divergence of bacteria, which, however, is not the case as shown by recent findings. The goal of this study was todetermine if DNA transfer efficiency is correlated with the levels of sequence identity.

Results: To compare the relative efficiency of exogenous DNA acquisition among closely related bacteria, we carried out phage-mediated transduction and plasmid-mediated transformation in representative Salmonella strains with different levels of relatedness. We found that the efficiency was remarkably variable even among genetically almost identical bacteria. Although there was a general tendency that more closely related DNA donor-recipient pairs had higher transduction efficiency, transformation efficiency exhibited over a thousand times difference among the closely related Salmonella strains.

Conclusion: DNA acquisition efficiency is greatly variable among bacteria that have as high as over 99\% identical genetic background, suggesting that bacterial speciation involves highly complex processes affected not only by whether beneficial exogenous DNA may exist in the environment but also the "readiness" of the bacteria to accept it.
\end{abstract}

Keywords: Bacterial speciation, Homologous recombination, Salmonella, Transduction, Transformation

\section{Background}

Speciation of bacteria, i.e., their divergence from the ancestor and evolution into new species, is facilitated by incorporation of laterally acquired genetic material into the genome, as demonstrated by comparative studies of model bacteria, such as Salmonella and other enteric bacteria [1-3]. Bacteria of the Salmonella genus have been

\footnotetext{
*Correspondence: grliu.natsumi@gmail.com; pandafengye@gmail.com; slliu@ucalgary.ca

${ }^{\dagger}$ Equal contributors

${ }^{1}$ Genomics Research Center (one of The State-Province Key Laboratories of Biomedicine-Pharmaceutics of China), Harbin Medical University, 157 Baojian Road, Harbin 150081, China

${ }^{2}$ Department of Biopharmaceutical Sciences, Harbin Medical University, Harbin, China

${ }^{3} \mathrm{HMU}-U C F M$ Centre for Infection and Genomics, Harbin Medical University, Harbin, China

Full list of author information is available at the end of the article
}

frequently used as ideal research models of bacterial genomic divergence and evolution owing to several advantages that fit such studies, including the close genetic relatedness and, conversely, distinct pathogenic properties of these bacteria. In addition, the extraordinarily large number of known genetic and pathogenic types of Salmonella makes the comparative studies informative and feasible.

Salmonella diverged from Escherichia coli more than 100 million years ago [4-6]; to date, more than 2500 serologically defined types, called serotypes or serovars, have been documented $[7,8]$. Genomic comparisons reveal that different Salmonella serotypes have highly similar overall genome structures, which are also similar to that of $E$. coli [9-12], validating the long speculated high level genomic conservation during long evolutionary times. When more detailed comparisons are made systematically

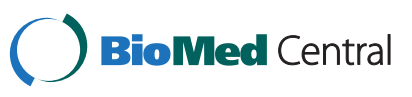


over the whole genome, specific differences can be found among even very closely related bacterial lineages [11,13-16]. Genomic differences can be classified essentially into two main categories: DNA sequence variations and distinct sets of insertions between the bacteria. It is well documented that monophyletic Salmonella serotypes (versus polyphyletic serotypes that contain genetically distinct lineages but are classified together due to their common serological features, such as Salmonella paratyphi B containing both single-host and broad-host infecting lineages that cause paratyphoid and gastroenteritis, respectively, in humans) may have "hallmark" insertions, such as the $134 \mathrm{~kb}$ SPI7 in most S. typhi isolates (S. paratyphi C and S. dublin have different versions of SPI7) [17-20]. Within a monophyletic Salmonella serotype, individual sub-lineages may also have their own unique insertions or combinations of them, as exemplified by the DT104 phage type of S. typhimurium for their possession of three insertions ST104, ST104B and ST64B, a combination not seen in other S. typhimurium sub-lineages [16,21]. All these facts suggest that, although bacteria have many chances to contact exogenous DNA in the environment and may even possibly have it moved into the cell via mechanisms such as bacteriophage-mediated transduction and plasmid-mediated transformation, the recipient may or may not have it incorporated into the genome regardless of whether or not the recipient might gain better fitness to the environment by having it. For example, although in vitro recombination efficiency depends linearly on the levels of the sequence similarity of the DNA strands, whether this linearity also exists in the exogenous DNA incorporation process inside a bacterial cell is unknown.

In this study, we assessed the efficiency of exogenous DNA acquisition by phage-mediated transduction and plasmid-mediated transformation in selected bacterial strains to establish whether DNA transfer efficiency might be correlated with the levels of sequence identity. We found that the efficiency was remarkably different among even very closely related bacteria. We conclude that DNA acquisition efficiency is greatly variable among bacteria that have as high as over $99 \%$ identical genetic background, which implies that bacterial speciation involves highly complex processes affected not only by whether beneficial exogenous DNA may exist in the environment but also the "readiness" of the bacteria to accept it.

\section{Results}

Transduction frequency and its correlation with sequence similarity: general tendency and strain-specific efficiency We transferred five Tn10-inserted genes, including flgL, treA, ompC, hisA and purG, from S. typhimurium LT2 to the recipient strains (Table 1). To assess whether the five genes might be representative of the whole genome regarding the divergence among the Salmonella strains used in this study, we concatenated the sequences of the five genes and constructed a phylogenetic tree (Figure 1A) for comparison with the tree that was based on the core genes of the whole genome (Figure 1B). For the strains for which no whole genome sequences were available for tree construction, we used the published sequences of strains of the same serovar, such as S. agona strain SL483 instead of SARB1 (Table 1). The two trees demonstrated essentially the same genetic relatedness among the bacteria, justifying the use of these Salmonella strains, although the five genes had different levels of divergence among the Salmonella strains (Table 2).

Recombination frequencies as reflected by the relative numbers of transductants on LB plates varied among thefive genes in a given recipient; however, the differences between strains were much greater (Table 3). As would be expected, S. typhimurium 14028S exhibited the highest frequency of recombination with the DNA from S. typhimurium LT2 among all recipient strainsand we did not get any transductants from S. bongori SARC12 (the most distantly related species with $S$. typhimurium among all Salmonella lineages), althoughthis latter strain did express the $\mathrm{O} 12$ antigen after transformation by pPR1347 (See Methods). Notably, however, although 14028 S has nearly identical genomic sequence to LT2, its recombination frequency was as low as merely one tenth that of LT2. A similar situation was seen with $S$. enteritidis LK5, whose sequence divergence is only 0.012 from S. typhimurium LT2 but its recombination frequency with LT2 was even lower than S. arizonae SARC5 with LT2, although $S$. arizonaeis a serovar from subgroup IIIa, which is much more divergent than $S$. enteritidis from S. typhimurium (see Figure 1). Another notable observation was that we did not obtain any transductants from S. typhi Ty2 even though we tried numerous times, which however was consistent with our previous findings that we had to disrupt the mutL gene of S. typhi Ty2 in order to obtain transductants in the transduction experiments with the donor DNA from S. typhimurium LT2 when we were constructing a physical map for S. typhi Ty2 [18].

As a whole in the experiments described above, although we saw a general tendency of higher transduction efficiency with closer genetic relationships between the donor and recipient bacterial strains, a linear model was not supported by our data (i.e., the relationship was not linear; Figure 2). Especially, the results out of $S$. typhimurium LT2 and $14028 \mathrm{~S}$ seem to demonstrate that the transduction efficiency is rather strain-specific. We thus considered evaluating bacterial strain specificity by involving multiple strains of a Salmonella lineage and between very closely related lineages, i.e., S. gallinarum and S. pullorum. 
Table 1 Bacterial strains used in this study*

\begin{tabular}{lcc}
\hline Strain & Accession number & Relationship with S. typhimurium LT2 \\
\hline S. typhimurium LT2 & AE006468.1 & - \\
S. typhimurium 14028S & CP001363.1 & Same serovar $(1,4,[5], 12: 1: 1,2)$ \\
S. typhi Ty2 & AE014613.1 & Same subgroup (I) \\
S. paratyphi A ATCC9150 & CP000026.1 \\
S. paratyphi B SPB7 & CP000886.1 & Same subgroup (I) \\
S. paratyphi C RKS4594 & CP000857.1 & Same serogroup (04) \\
S. agona SL483 & CP001138.1 & Same subgroup (I) \\
S. agona SARB1 & N/A & Same serogroup (04) \\
S. dublinCT_02021853 & CP001144.1 & Same serogroup (04) \\
S. dublin TYT3627 & N/A & Same subgroup (I) \\
S. enteritidis P125109 & AM933172.1 & Same subgroup (I) \\
S. enteritids LK5 & N/A & Same subgroup (I) \\
S. pullorum RKS5078 & CP003047.1 & Same subgroup (I) \\
S. gallinarum287/91 & AM933173.1 & Same subgroup (I) \\
S. arizonae RKS2980 & CP000880.1 & Same subgroup (I) \\
S. arizonae SARC5 & N/A & Closely related subgroup (IIla) \\
S. bongori NCTC 12419 & FR877557.1 & Closely related subgroup (IIla) \\
S. bongori SARC12 & CP006692 & Distantly related subgroup (V) \\
\hline
\end{tabular}

*See more detailed information on these bacterial strains at http://www.ucalgary.ca/ kesander.

Transduction frequency between S. gallinarum and S. pullorum: variable efficiency among individual strains S. gallinarum and S. pullorum have a common antigenic formula, 1,9,12:-:-, the former causing typhoid and the latter causing pullorum disease in fowl. They were originally treated as separate species [22] but have since the mid 1980s been classified into the same serovar of the same subspecies (i.e., S. enterica subspecies enterica Serovar Gallinarum as separate biovars Gallinarum and Pullorum, respectively [8]). However, their distinct biological properties, i.e., causing entirely different diseases, unambiguously distinguish them as different organisms. Recently our work reveals that the two pathogens have accumulated distinct sets of mutations, including different pseudogenes [15,23], which further demonstrated their genetic divergence. We moved the Tn10-inserted ompD gene first from $S$. typhimurium LT2 to four wild type strains each of S. pullorum (including strain RKS5078 [23,24]) and S. gallinarum (including strain 287/91 [25],) and then from one of the eight strains to the other seven strains; this process was repeated for each of the eight strains. We observed a tendency that transduction frequency was higher in a donor-recipient pair of strains within S. pullorum or within S. gallinarum than between S. pullorum and S. gallinarum strains, although not all of these differences were statistically significant (Figure 3A). To validate this observation and rule out the possibility that a particular genomic DNA segment (e.g., ompD in
Figure 3A) or some bacterial strains might have biases, we used Tn10-inserted leu, bio, oxrA and cys $A$ as donor DNA, with $o m p D$ also included as donor DNA for a comparison, in the second set of transduction experiments with larger numbers of S. pullorum and S. gallinarum strains. Again, the transduction frequency was lower between S. pullorum and S. gallinarum than within S. gallinarum or S. pullorum, but, similar to the above experiments, not all of the differences were statistically significant (Figure 3B \& C).

\section{Transformation efficiency among individual Salmonella strains}

As transduction frequency reflects a combined result of DNA taking up capability and recombination efficiency, we wondered whether the non-linearity of transduction frequency with the level of relatedness of the bacteria might have mainly resulted from differential capability of the bacteria to take up DNA from the environment into the cell. To look into this, we transformed representative strains with the plasmid pQE30, which does not have homologous sequences with the genomes of the bacterial strains used in the study, and compared the transformation efficiency among them. Intriguingly, the transformation rates differed more than one thousand times among the tested bacteria, e.g., as low as ca. $8.3 \times 10^{-7}$ in S. enteritidis LK5 andas high as ca.1.3 $\times 10^{-3} \mathrm{inS}$. arizonae SARC5 (Table 4). 

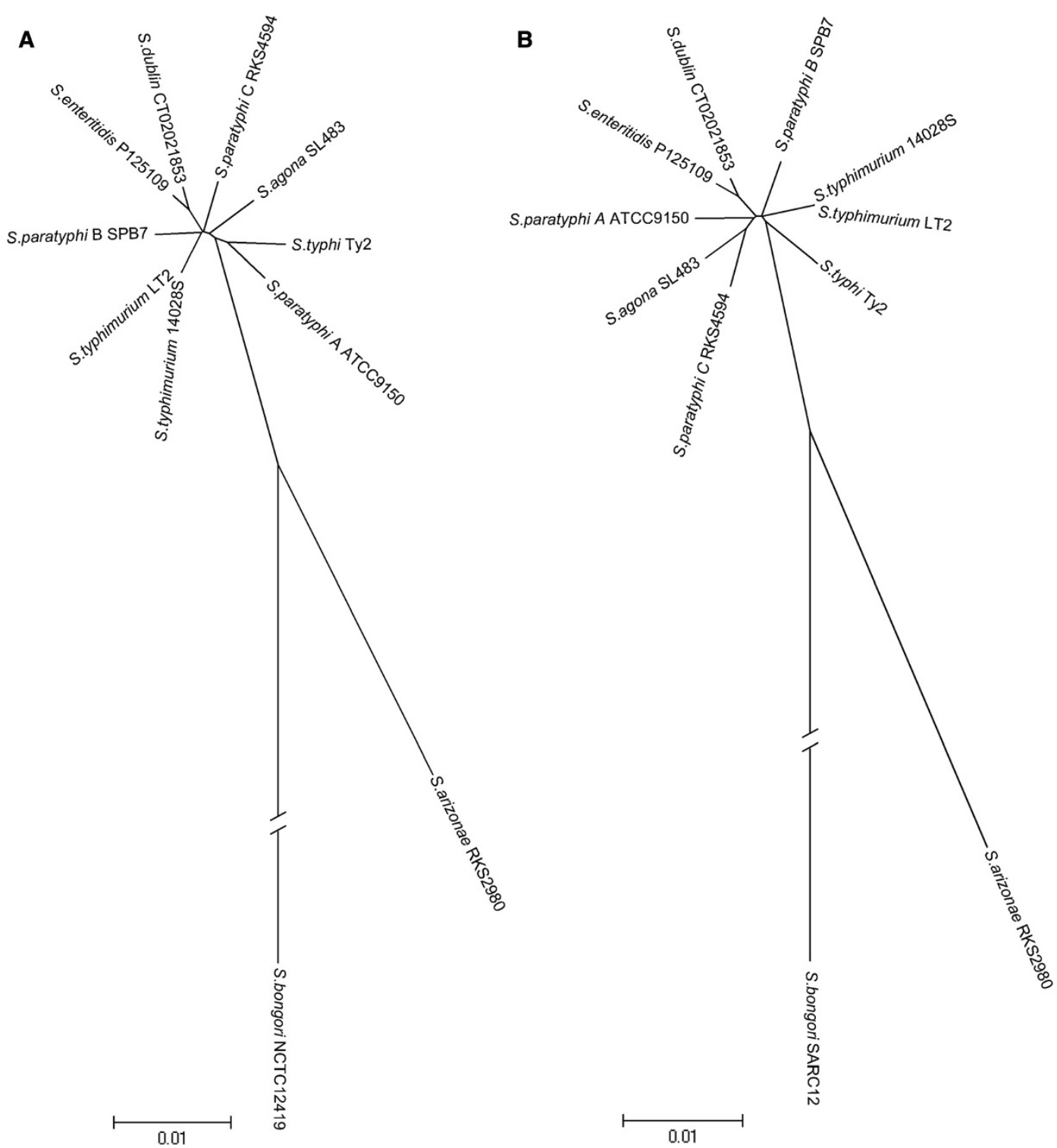

Figure 1 Phylogenetic trees of Salmonella strains involved in transduction frequency comparison (see main text). A, Phylogenetic tree based on core genes of the whole genome; $\mathbf{B}$, phylogenetic tree based on the five genes.

\section{Discussion}

Two classes of genomic changes are associated with the phylogenetic divergence and evolution of bacteria acquisition of laterally transferred DNA and nucleotide substitution, with the former being the primary driver of bacterial speciation, i.e., the process and consequence of bacterial development into a nascent biological species.

The biological species is defined on the basis of sexual reproduction potential of the organisms [26,27], i.e., each species is separated from others through reproductive barriers. This definition of species works well for many plants and animals but not so much for bacteria owing to the mostly non-sexual reproduction modes of bacteria. As bacteria acquire much of the genetic novelty through homologous recombination of laterally transferred DNA, it seems reasonable to presume that recombination efficiency among bacteria should be falling gradually with increasing sequence divergence. Several lines of evidence exist to support this presumption in Escherichia, Bacillus and Streptococcus [28-30]. If so, bacterial speciation would be a gradual process, leading to continuous divergence of the bacterial genomes without genetic boundaries to delineate bacteria into discrete clusters, i.e., bacterial species would have to be arbitrary. However, our recent work has demonstrated the existence of clear-cut genetic boundaries among bacteria as closely related as the Salmonella 
Table 2 Sequence divergence of the five genes between S. typhimurium LT2 and the recipient strains

\begin{tabular}{|c|c|c|c|c|c|c|c|}
\hline Recipient strain & $f l g L$ & treA & hisA & ompC & purG & Average & SD \\
\hline S. typhimurium LT2 & - & - & - & - & - & - & - \\
\hline S. typhimurium $14028 \mathrm{~s}$ & 0 & 0.0006 & 0 & 0 & 0 & 0.0001 & 0.0003 \\
\hline S. paratyphi B SPB7 & 0.0094 & 0.0093 & 0.0136 & 0.0088 & 0.0103 & 0.0103 & 0.0019 \\
\hline S. agona SARB1 & 0.0105 & 0.0146 & 0.0163 & 0.0202 & 0.0085 & 0.014 & 0.0047 \\
\hline S. dublin TYT3627 & 0.0084 & 0.0088 & 0.0081 & 0.0088 & 0.0082 & 0.0085 & 0.0003 \\
\hline S. enteritidis LK5 & 0.0126 & 0.0088 & 0.0122 & 0.0202 & 0.0082 & 0.0124 & 0.0048 \\
\hline S. paratyphi C RKS4594 & 0.0063 & 0.0128 & 0.0108 & 0.0202 & 0.0113 & 0.0123 & 0.0051 \\
\hline S. paratyphi A ATCC9150 & 0.0073 & 0.0123 & 0.0136 & 0.0053 & 0.0116 & 0.01 & 0.0035 \\
\hline S. typhi Ty2 & 0.0073 & 0.0169 & 0.0136 & 0.0053 & 0.0111 & 0.0108 & 0.0047 \\
\hline S. arizonae SARC5 & 0.0692 & 0.0736 & 0.0637 & 0.0325 & 0.0598 & 0.0598 & 0.0161 \\
\hline S. bongori SARC12 & 0.1143 & 0.0362 & 0.061 & 0.0554 & 0.0769 & 0.0688 & 0.0293 \\
\hline
\end{tabular}

lineages [31], indicating that a fundamental question still remains regarding molecular mechanisms involved in bacterial speciation, especially the DNA acquisition capability of the bacteria.

Based on our hypothesis of genetic boundaries and the experimental evidence [31], we propose that biological species should be non-continuous and non-overlapping units of organisms with sufficient similarities among members of the same species and radically distinguishing features from organisms of other species. Bacteria, though as essentially non-sexual organisms, should also be genetically isolated from one another as species. To date, thousands of bacterial strains have been sequenced, with a full picture of the genomic divergence among them awaiting systematic analyses. We believe that genomic divergence among bacteria is not continuous and clear-cut boundaries ought to exist to demarcate bacteria into discrete species. In our Adopt-Adapt Model of bacterial speciation $[17,32,33]$, we dissect the process into two overall stages: Adopt, in which bacteria "adopt" exogenous
DNA from the environment to gain beneficial genetic traits, and Adapt, in which bacteria make adjustments to "adapt" to the genetic and biological changes brought about by the novel genetic material, including genomic rearrangements (if the adopted DNA segment was large such as larger than $100 \mathrm{~kb}$ [34]) and genetic separation from the ancestral strain as reflected by the formation of the genetic boundaries [31]. According to this model, exogenous DNA acquisition is the first step; the present study demonstrates that the stochastic lateral DNA acquisition events may not be destined to take place even though the "right" recipient might meet the "right" donor at the "right" time (e.g., when the recipient is in bad need of certain trait that could be donated by a potential donor nearby in the environment). Rather, this event might be under strict control, although the molecular mechanisms are largely unknown. In this study, we assessed correlations between genomic sequence divergence and transduction or transformation frequency among closely related bacteria, anticipating either (i) a linear model with

Table 3 Relative transduction frequency of Salmonella strains for the five genes

\begin{tabular}{|c|c|c|c|c|c|c|}
\hline Strain & $f l g L$ & treA & ompC & hisA & purG & mean \pm sd \\
\hline S. typhimurium LT2 & 1 & 1 & 1 & 1 & 1 & 1 \\
\hline S. typhimurium $14028 \mathrm{~s}$ & $1.17 \times 10^{-1}$ & $0.60 \times 10^{-1}$ & $0.92 \times 10^{-1}$ & $0.79 \times 10^{-1}$ & $0.73 \times 10^{-1}$ & $(8.42 \pm 2.15) \times 10^{-2}$ \\
\hline S. paratyphi B SPB7 & $0.42 \times 10^{-2}$ & $0.24 \times 10^{-2}$ & $1.03 \times 10^{-2}$ & $1.36 \times 10^{-2}$ & $1.68 \times 10^{-3}$ & $(9.46 \pm 6.11) \times 10^{-3}$ \\
\hline S. agona SARB1 & $0.66 \times 10^{-3}$ & $0.11 \times 10^{-3}$ & $0.61 \times 10^{-3}$ & $1.45 \times 10^{-3}$ & $0.15 \times 10^{-3}$ & $(5.94 \pm 5.42) \times 10^{-4}$ \\
\hline S. dublin TYT3627 & $4.30 \times 10^{-3}$ & $1.92 \times 10^{-3}$ & $3.64 \times 10^{-3}$ & $3.50 \times 10^{-3}$ & $3.29 \times 10^{-3}$ & $(3.33 \pm 0.87) \times 10^{-3}$ \\
\hline S. enteritidis LK5 & $2.20 \times 10^{-5}$ & $0.88 \times 10^{-5}$ & $0.00 \times 10^{-5}$ & $1.80 \times 10^{-5}$ & $1.05 \times 10^{-5}$ & $(1.19 \pm 0.86) \times 10^{-5}$ \\
\hline S. paratyphi C RKS4594 & $0.93 \times 10^{-3}$ & $0.76 \times 10^{-3}$ & $1.22 \times 10^{-3}$ & $0.13 \times 10^{-3}$ & $0.48 \times 10^{-3}$ & $(7.02 \pm 4.19) \times 10^{-4}$ \\
\hline S. paratyphi A ATCC9150 & $1.54 \times 10^{-4}$ & $2.37 \times 10^{-4}$ & $1.04 \times 10^{-4}$ & $0.63 \times 10^{-4}$ & $1.15 \times 10^{-4}$ & $(1.35 \pm 0.66) \times 10^{-4}$ \\
\hline S. typhi Tyz & $<1.00 \times 10^{-6}$ & $<1.00 \times 10^{-6}$ & $<1.00 \times 10^{-6}$ & $<1.00 \times 10^{-6}$ & $<1.00 \times 10^{-5}$ & $<1.00 \times 10^{-6}$ \\
\hline S. arizonae SARC5 & $8.15 \times 10^{-4}$ & $3.08 \times 10^{-4}$ & $5.53 \times 10^{-4}$ & $1.17 \times 10^{-4}$ & $3.46 \times 10^{-4}$ & $(4.28 \pm 2.66) \times 10^{-4}$ \\
\hline S. bongori SARC 12 & $<1.00 \times 10^{-6}$ & $<1.00 \times 10^{-6}$ & $<1.00 \times 10^{-6}$ & $<1.00 \times 10^{-6}$ & $<1.00 \times 10^{-6}$ & $<1.00 \times 10^{-6}$ \\
\hline
\end{tabular}

Note: The relative transduction frequency listed in the table refers to relative transduction rate compared to LT2. 


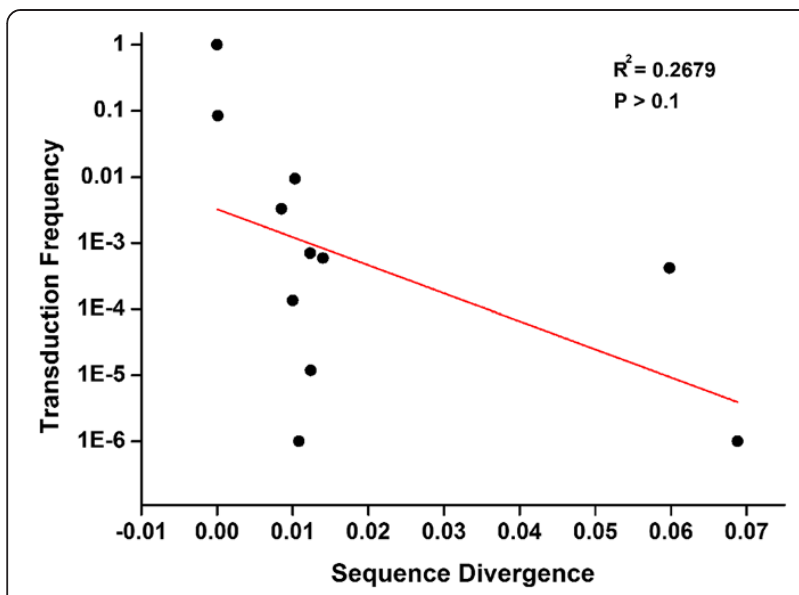

Figure 2 Transduction frequencies against levels of relatedness among the Salmonella strains.

falling transduction or transformation frequency in correlation with increasing genomic divergence; or (ii) a non-linear model; we observed the latter.

To interpret these observations, we may divide the exogenous DNA acquisition process into two steps. In the first step, exogenous DNA enters the cell and escapes degradation by restriction enzymes or other defense systems. The next step includes hetero duplex molecule formation, replication and segregation to daughter cells. This second step is controlled negatively by mismatch repair (MMR) proteins, such as $M u t S$ and $M u t L$, and positively by the induction of SOS system. As MMR and SOS genes are highly conserved in bacteria, they are supposed to function equally in all tested Salmonella strains. Consequently, the second step here should mainly be determined by the sequence divergence between the donor and recipient. It is therefore reasonable to presume that the non-linear correlation between recombination efficiency and genomic divergence should be due to differences in the first step, i.e., entry of exogenous DNA into the bacterial cell. As transduction and transformation use different mechanisms to bring DNA into the cell across the cell wall and membrane, the plasmid transformation may not effectively simulate the first step of P22-mediated homologous recombination. Nevertheless, when we divided the transduction frequency by the transformation frequency in a given strain, the "normalized" results fitted the linear model slightly better (calculation not shown). Taken together, our results demonstrate that the linear model may hold true only when recombination efficiency is determined exclusively by sequence divergence, although there seems no such a case in the real world. As this study focused on only DNA transfer events, systematic elucidation of the bacterial speciation mechanisms requires investigation of also other strain differences such as level of gene expression for competency/DNA recombination, which is under study in our laboratory. Since transformation and transduction are the two main mechanisms for DNA uptake by bacteria and even very closely related bacteria may exhibit distinct performance in recombination as demonstrated in this study, it is possible that subpopulations or even individual cells of a bacterial species might have begun to form genetic barriers against exogenous DNA to stabilize the bio-system within the cell or a subpopulation or to continue the speciation process to become a nascent species.

\section{Conclusion}

DNA acquisition efficiency is variable among closely related bacteria, suggesting that bacterial speciation involves highly complex processes affected not only by whether beneficial exogenous DNA may exist in the environment but also the "readiness" of the bacteria to accept it.

\section{Methods}

\section{Bacterial and phage strains}

The Salmonella strains used in this study are listed in Table 1; more detailed information on these bacterial strains can be found at the Salmonella Genetic Stock Center (SGSC; http://www.ucalgary.ca/ kesander/). The bacterial strains were cultured at $37^{\circ} \mathrm{C}$ and the bacteriophage P22 strain (HT105/1 int-201) used in the transduction experiments was routinely grown on $S$. typhimurium LT2.

\section{Phage P22-mediated transduction}

P22-mediated transduction was used to mediate homologous recombination between donor and recipient strains as previously described $[35,36]$. The primary donor strains were derivatives of S. typhimurium LT2 [37,38]. Five such derivative strains were used, having $\operatorname{Tn} 10$ (with tetracycline resistance) inserted within gene flgL, tre $A, o m p C$, his $A$ or purG. After P22 infection of the secondary donor strains (S. gallinarum or S. pullorum strains used as donors of the Tn10-inserted genes to the S. gallinarum or S. pullorum recipient strains; see Results), the phage lysate was used to infect recipient strains. Construction of the secondary donor strains from the Tn10-inserted LT2 derivatives and preparation of phage lysate were done as described [36].

As P22 can only infect the bacteria that express the O12 antigen, we first transformed the O12 recipient strains by a cosmid, pPR1347, that carries the O12 antigen gene [39]; details of the experimental procedure can be found in literature [36]. Briefly, the E. coli strain that carries pPR1347 was cultured in LB broth overnight. The cosmid was extracted by alkaline lysis method and was transferred into S. paratyphi C RKS5478, S. arizonae SARC5 and S. bongori SARC12; all of the three 

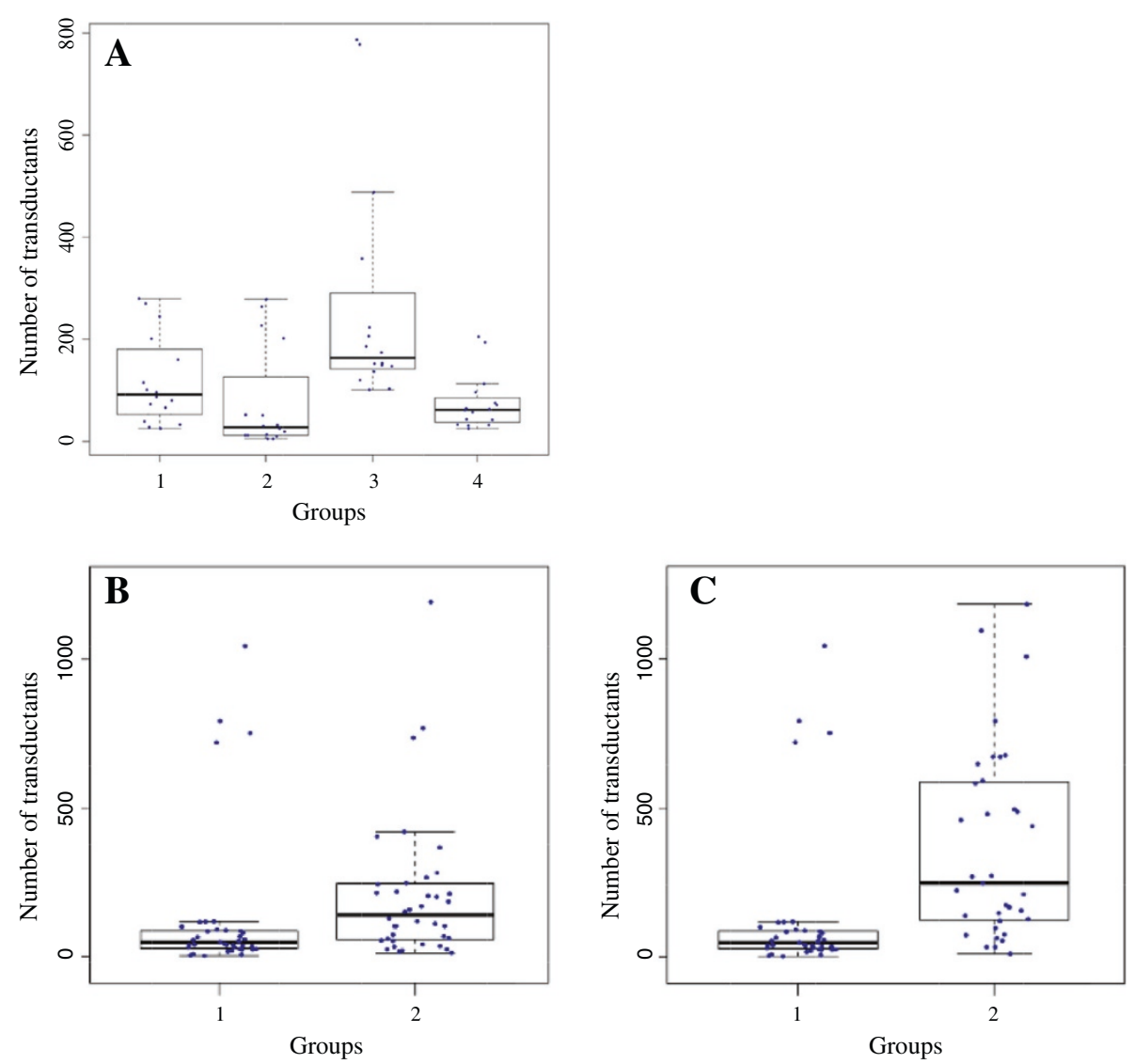

Figure 3 Comparisons of recombination efficiency reflected by transduction frequencies, with the points representing the numbers of transductants. A, Transduction of ompD159 between S. gallinarum and S. pullorum (see text for more details). Groups: 1, S. pullorum recipients and S. pullorum DNA; 2, S. pullorum recipients and S. gallinarum DNA; 3, S. gallinarum recipients and S. gallinarum DNA; 4, S. gallinarum recipients and S. pullorum DNA. Note that group 3 has the largest numbers of recipients (groups 2 vs 3, $p=0.007$; groups 3 vs 4, p = 0.000), reflecting significantly higher recombination efficiency of S. gallinarum DNA into the S. gallinarum genome (group 3) than S. gallinarum DNA to the S. pullorum genome (group 2) or than S. pullorum DNA to the S. gallinarum genome (group 4). Group 1 had a similar tendency as group 3, although the differences were not statistically significant (groups 1 vs 2, $p=0.079$; groups 1 vs 4, $p=0.071$ ). B. Transduction with S. pullorumas the recipient and S. pullorum or S. gallinarumas the donor. Groups: 1, S. pullorum recipients with DNA fromS. gallinarum 287/91; 2, S. pullorum recipients with DNA from S. pullorum RKS5078 (groups 1 vs 2 , $p=0.009$ ). C, Transduction with S. pullorum or S. gallinarumstrains as the recipient and donor DNA from S. gallinarum. Groups: 1, S. pullorum recipients with DNA from S. gallinarum strain 287/91; 2, S. gallinarum recipients with DNA from S. gallinarum strain 287/91 (groups 1 vs 2, p=0.000).

Table 4 Frequencies of transformation among the recipient strains for the same donor DNA

\begin{tabular}{lc}
\hline Strain & Transformation frequency \\
\hline S. typhimurium LT2 & $(4.30 \pm 1.15) \times 10^{-4}$ \\
S. typhimurium 14028S & $(5.08 \pm 0.72) \times 10^{-6}$ \\
S. paratyphi B SPB7 & $(4.10 \pm 1.40) \times 10^{-4}$ \\
S. agona SARB1 & $(2.25 \pm 0.90) \times 10^{-6}$ \\
S. dublin TYT3627 & $(2.46 \pm 0.91) \times 10^{-4}$ \\
S. enteritids LK5 & $(8.33 \pm 1.44) \times 10^{-7}$ \\
S. paratyphi C RKS4594 & $(1.44 \pm 0.01) \times 10^{-4}$ \\
S.paratyphi A ATCC9150 & $(2.93 \pm 1.05) \times 10^{-4}$ \\
S. typhi Ty2 & $(8.15 \pm 1.43) \times 10^{-4}$ \\
S. arizonae SARC5 & $(1.32 \pm 0.51) \times 10^{-3}$ \\
S. bongori SARC12 & $(1.58 \pm 0.45) \times 10^{-3}$ \\
\hline
\end{tabular}

bacterial strains expressed O12 after the transformation by pPR1347.

The transduction frequency was determined as follows. The recipient strains were cultured in LB broth till OD600 reaching 2.0. Then the bacteria were mixed with P22 phage lysate at an MOI (multiplicity of infection) of 0.01 , plated onto LB medium containing tetracycline $(15 \mu \mathrm{g} / \mathrm{ml})$ and incubated at $37^{\circ} \mathrm{C}$ for $18 \mathrm{~h}$. Because all recipient strains were sensitive to tetracycline, only clones that have gone through successful homologous recombination would be able to grow on the tetracycline-containing plate. The relative transduction frequency of each recipient strain was calculated by dividing the number of its transductants by the number of LT2 transductants transduced by the same lot and amount of the phage lysate. Each experiment was repeated five times. 


\section{Transformation}

The plasmid pQE30, which carries ampicillin resistance, was used for transformation. The recipient bacteria were cultured in LB broth until OD600 reached 0.4. Competence was induced by thawing the culture on ice for $1 \mathrm{~min}$. A volume of $80 \mu \mathrm{l}$ competent cells were mixed with $2 \mu \mathrm{l}$ plasmid pQE30 and electroporated at $25 \mu \mathrm{F}$ capacitance, $2.5 \mathrm{kv}$ and $200 \mathrm{ohm}$ resistance, followed immediately by the addition of $320 \mu \mathrm{l}$ fresh LB medium. The bacteria were incubated on $37^{\circ} \mathrm{C}$ with agitation of $85 \mathrm{rpm}$ for 1 hour. Then the bacteria were spread onto LB agar plates containing ampicillin $(100 \mu \mathrm{g} / \mathrm{ml})$ and incubated at $37^{\circ} \mathrm{C}$ overnight. As all recipient strains used were sensitive to ampicillin, only successful transformants could grow on ampicillin plates. The transformation frequency was calculated by dividing the number of transformants by the number of competent cells of the same volume grown on pure LB plate. Each experiment was repeated five times.

\section{Calculation of sequence divergence}

The genome sequences for comparison were downloaded from Genbank database, with the accession numbers being listed in Table 1. The genome sequence of $S$. agona SARB1, S. dublin TYT3627, S. enteritidis LK5 are not available in public database yet, so we use the published strains of the same serovar instead (see Table 1). Because S. bongori SARC12 doesn't have any published relative of the same serovar, we sequenced its genome by using $\mathrm{SOLiD}^{\mathrm{m}}{ }^{3.0}$ sequencer. Briefly, we sheared the bacterial genomic DNA into fragments of $2 \sim 4 \mathrm{~kb}$ in size and sequenced both ends of the fragments following $\mathrm{SOLiD}^{\mathrm{ma}} 3.02 \times 50$ bp mate-pair sequencing protocol. The raw reads were assembled into draft genome by using the software SOLiD ${ }^{\text {Ta }}$ System de novo Accessory Tools 2.0 (http://solidsoftwaretools.com/gf/project/denovo/). The gaps between the obtained contigs were closed by PCR.

We calculated the sequence divergence between the compared strains by two approaches. The first approach was based on five genes only. The nucleotide sequences of flgL, treA, ompC, hisA and purG were extracted from the complete genomes, aligned by CLUSTALW, and then concatenated together. The alignment was input into MEGA5 for constructing the phylogenetic tree. The Jukes-Cantor substitution model was adopted and the neighbor-joining algorithm was implemented. The second approach was based on all conserved orthologous genes. We chose LT2 as the reference genome and searched its protein-coding sequences against other strains by BLAST. The threshold of the BLAST search was as follows: the e-value must be smaller than $1 \times 10^{-10}$, the identity of the amino acid must be larger than $80 \%$ and the alignment length must be longer than $80 \%$ of the gene length. The conserved genes among all strains were then aligned by CLUSTALW and were concatenated together. Finally the alignment was input into MEGA5 and the construction of the phylogenetic tree was built with the same parameter to the first approach.

\section{Availability of supporting data}

The genome sequence of $S$. bongori SARC12 is available the Genbank database under the accession number CP006692. The phylogenetic trees supporting the results of this article are available in the TreeBASE repository, http://purl.org/phylo/treebase/phylows/study/ TB2:S15939? $x$-access-code $=26 f 7 b b 0963 b f 24 c f f 2 e 944 f e 3$ 065c5ec\&format $=$ html.

Competing interests

The authors declare that they have no competing interests.

\section{Authors' contributions}

$H X B$ and LT carried out the experimental work and genomic sequence analysis. $L Y, X Y W, Y L$ and $X D$ participated in the experimental work. AL conducted statistical analysis. RNJ, YGL, DLZ, YF and GRL participated in data analysis. YF participated in the designing of the study. HXB, LT and YF contributed to drafting the manuscript. SLL conceived of and designed the study and wrote the manuscript. All authors read and approved the final manuscript.

\section{Acknowledgments}

This work was supported by a grant from the National Natural Science Foundation of China (81201248) to YF; a grant from the Heilongjiang Innovation Endowment Award for graduate studies (YJSCX2012-197HLJ) to LT; a grant from NSFC (30970078) and a grant of Natural Science Foundation of Heilongjiang Province of China to GRL; and NSFC grants (30970119, 81030029, 81271786, 81161120416), and a Specialized Research Fund for the Doctoral Program of Higher Education (SRFDP, 20092307110001) to SLL.

\section{Author details}

${ }^{1}$ Genomics Research Center (one of The State-Province Key Laboratories of Biomedicine-Pharmaceutics of China), Harbin Medical University, 157 Baojian Road, Harbin 150081, China. ${ }^{2}$ Department of Biopharmaceutical Sciences, Harbin Medical University, Harbin, China. ${ }^{3} \mathrm{HMU}$-UCFM Centre for Infection and Genomics, Harbin Medical University, Harbin, China. ${ }^{4}$ Department of Infectious Diseases of First Affiliated Hospital, Harbin Medical University, Harbin, China. ${ }^{5}$ Department of Biostatistics, Harbin Medical University, Harbin, China. ${ }^{6}$ College of Pharmacy of Daqing Campus, Harbin Medical University, Harbin, China. ${ }^{7}$ Department of Biochemistry and Molecular Biology, University of Calgary, Calgary, Canada. ${ }^{8}$ Department of Microbiology and Infectious Diseases, University of Calgary, Calgary, Canada. ${ }^{9}$ Institute for Translational Medicine, Zhejiang University School of Medicine, Hangzhou, China.

Received: 18 July 2013 Accepted: 10 June 2014

Published: 14 June 2014

References

1. Groisman EA, Saier MH Jr, Ochman H: Horizontal transfer of a phosphatase gene as evidence for mosaic structure of the Salmonella genome. EMBO J 1992, 11(4):1309-1316.

2. Ochman H, Bergthorsson U: Genome evolution in enteric bacteria. Curr Opin Genet Dev 1995, 5(6):734-738.

3. Feng Y, Liu S-L: Pathogenic Salmonella. In Omics, Microbial Modeling, and Technologies for Food-borne Pathogens. Edited by Yan X, Juneja V, Fratamico PM, Smith J. Lancaster, Pennsylvania, USA: DEStech Publications, Inc; 2011:43-68.

4. Ochman H, Wilson AC: Evolution in bacteria: evidence for a universal substitution rate in cellular genomes. J Mol Evol 1987, 26(1-2):74-86. 
5. Doolittle RF, Feng DF, Tsang S, Cho G, Little E: Determining divergence times of the major kingdoms of living organisms with a protein clock. Science (New York, NY) 1996, 271(5248):470-477.

6. Feng DF, Cho G, Doolittle RF: Determining divergence times with a protein clock: update and reevaluation. Proc Natl Acad Sci U S A 1997, 94(24):13028-13033.

7. Popoff MY, Le Minor L: Antigenic formulas of the Salmonella serovars. In WHO Collaborating Centre for Reference and Research on Salmonella. 8th edition. Paris: Pasteur Institute; 2001

8. Popoff MY, Le Minor LE: Genus XXXIII. Salmonella. In Bergey's Manual of Systematic Bacteriology, Volume 2. 2nd edition. Edited by Brenner DJ, Krieg NR, Stanley JT. New York: Springer; 2005:764-799.

9. Liu SL, Hessel A, Sanderson KE: Genomic mapping with I-Ceu I, an intron-encoded endonuclease specific for genes for ribosomal RNA in Salmonella spp., Escherichia coli, and other bacteria. Proc Natl Acad Sci U S A 1993, 90(14):6874-6878

10. Liu SL, Schryvers AB, Sanderson KE, Johnston RN: Bacterial phylogenetic clusters revealed by genome structure. J Bacterio/ 1999, 181(21):6747-6755

11. McClelland M, Sanderson KE, Spieth J, Clifton SW, Latreille P, Courtney L, Porwollik S, Ali J, Dante M, Du F, Hou S, Layman D, Leonard S, Nguyen C, Scott K, Holmes A, Grewal N, Mulvaney E, Ryan E, Sun H, Florea L, Miller W, Stoneking T, Nhan M, Waterston R, Wilson RK: Complete genome sequence of Salmonella enterica serovar Typhimurium LT2. Nature 2001 413(6858):852-856

12. Blattner FR, Plunkett $G$ 3rd, Bloch CA, Perna NT, Burland V, Riley M, Collado-Vides J, Glasner JD, Rode CK, Mayhew GF, Gregor J, Davis NW, Kirkpatrick HA, Goeden MA, Rose DJ, Mau B, Shao Y: The complete genome sequence of Escherichia coli K-12. Science (New York, NY) 1997, 277(5331):1453-1474.

13. McClelland M, Sanderson KE, Clifton SW, Latreille P, Porwollik S, Sabo A, Meyer R, Bieri T, Ozersky P, McLellan M, Harkins CR, Wang C, Nguyen C, Berghoff A, Elliott G, Kohlberg S, Strong C, Du F, Carter J, Kremizki C, Layman D, Leonard S, Sun H, Fulton L, Nash W, Miner T, Minx P, Delehaunty $K$, Fronick $C$, Magrini $V$, et al: Comparison of genome degradation in Paratyphi A and Typhi, human-restricted serovars of Salmonella enterica that cause typhoid. Nat Genet 2004, 36(12):1268-1274.

14. Deng W, Liou SR, Plunkett G 3rd, Mayhew GF, Rose DJ, Burland V, Kodoyianni V, Schwartz DC, Blattner FR: Comparative genomics of Salmonella enterica serovar Typhi strains Ty2 and CT18. J Bacteriol 2003, 185(7):2330-2337

15. Feng Y, Johnston RN, Liu GR, Liu SL: Genomic comparison between Salmonella Gallinarum and Pullorum: differential pseudogene formation under common host restriction. PLoS One 2013, 8(3):e59427.

16. Zhao EY, Bao HX, Tang JL, Zou QH, Liu WQ, Zhu DL, Chin J, Dong YY, Li YG, Cao FL, Poppe C, Sanderson KE, Johnston RN, Zhou D, Liu GR, Liu SL: Genomic comparison of Salmonella typhimurium DT104 with non-DT104 strains. Mol Genet Genomics 2013, 288(11):549-557.

17. Liu SL, Sanderson KE: Rearrangements in the genome of the bacterium Salmonella typhi. Proc Natl Acad Sci U S A 1995, 92(4):1018-1022.

18. Liu SL, Sanderson KE: Genomic cleavage map of Salmonella typhi Ty2. J Bacteriol 1995, 177(17):5099-5107.

19. Kothapalli S, Nair S, Alokam S, Pang T, Khakhria R, Woodward D, Johnson W, Stocker BA, Sanderson KE, Liu SL: Diversity of Genome Structure in Salmonella enterica Serovar Typhi Populations. J Bacteriol 2005, 187(8):2638-2650.

20. Nair S, Alokam S, Kothapalli S, Porwollik S, Proctor E, Choy C, McClelland M, Liu SL, Sanderson KE: Salmonella enterica serovar Typhi strains from which SPI7, a 134-kilobase island with genes for Vi exopolysaccharide and other functions, has been deleted. J Bacteriol 2004, 186(10):3214-3223.

21. Cooke FJ, Brown DJ, Fookes M, Pickard D, Ivens A, Wain J, Roberts M, Kingsley RA, Thomson NR, Dougan G: Characterization of the genomes of a diverse collection of Salmonella enterica serovar Typhimurium definitive phage type 104. J Bacteriol 2008, 190(24):8155-8162.

22. Le Minor L: Genus III. Salmonella. In Bergey's Manual of Systematic Bacteriology, Volume 1. Edited by Krieg NR. Baltimore: Williams \& Wilkins; 1984:427-458

23. Feng Y, Xu HF, Li QH, Zhang SY, Wang CX, Zhu DL, Cao FL, Li YG, Johnston RN, Zhou J, Liu GR, Liu SL: Complete genome sequence of Salmonella enterica serovar pullorum RKS5078. J Bacterio/ 2012, 194(3):744.
24. Wu KY, Liu GR, Liu WQ, Wang AQ, Zhan S, Sanderson KE, Johnston RN, Liu SL: The genome of Salmonella enterica serovar gallinarum: distinct insertions/deletions and rare rearrangements. J Bacterio/ 2005 187(14):4720-4727.

25. Thomson NR, Clayton DJ, Windhorst D, Vernikos G, Davidson S, Churcher C, Quail MA, Stevens M, Jones MA, Watson M, Barron A, Layton A, Pickard D, Kingsley RA, Bignell A, Clark L, Harris B, Ormond D, Abdellah Z, Brooks K, Cherevach I, Chillingworth T, Woodward J, Norberczak H, Lord A, Arrowsmith C, Jagels K, Moule S, Mungall K, Sanders M, et al: Comparative genome analysis of Salmonella Enteritidis PT4 and Salmonella Gallinarum 287/91 provides insights into evolutionary and host adaptation pathways. Genome Res 2008, 18(10):1624-1637.

26. Mayr E: Systematics and the Origin of Species from the Viewpoint of a Zoologist. New York: Columbia University Press; 1942.

27. Mayr E: What is a species, and what is not? Philos Trans $R$ Soc Lond B Biol Sci 1996, 63:262-277.

28. Majewski J, Zawadzki P, Pickerill P, Cohan FM, Dowson CG: Barriers to genetic exchange between bacterial species: Streptococcus pneumoniae transformation. J Bacterio/ 2000, 182(4):1016-1023.

29. Roberts MS, Cohan FM: The effect of DNA sequence divergence on sexual isolation in Bacillus. Genetics 1993, 134(2):401-408.

30. Vulic M, Dionisio F, Taddei F, Radman M: Molecular keys to speciation: DNA polymorphism and the control of genetic exchange in enterobacteria. Proc Natl Acad Sci U S A 1997, 94(18):9763-9767.

31. Tang JL, Li Y, Deng X, Johnston RN, Liu GR, Liu SL: Defining natural species of bacteria: clear-cut genomic boundaries revealed by a turning point in nucleotide sequence divergence. BMC Genomics 2013, 14:489.

32. Liu GR, Rahn A, Liu WQ, Sanderson KE, Johnston RN, Liu SL: The evolving genome of Salmonella enterica serovar Pullorum. J Bacterio/ 2002, 184(10):2626-2633.

33. Chen F, Liu WQ, Eisenstark A, Johnston RN, Liu GR, Liu SL: Multiple genetic switches spontaneously modulating bacterial mutability. BMC Evol Biol 2010, 10:277.

34. Liu SL, Sanderson KE: Highly plastic chromosomal organization in Salmonella typhi. Proc Natl Acad Sci U S A 1996, 93(19):10303-10308.

35. Liu SL, Sanderson KE: A physical map of the Salmonella typhimurium LT2 genome made by using Xbal analysis. J Bacteriol 1992, 174(5):1662-1672.

36. Liu SL: Physical mapping of Salmonella genomes. Methods Mol Biol 2007, 394:39-58.

37. Sanderson KE, Hessel A, Liu S-L, Rudd KE: The genetic map of Salmonella typhimurium, Edition III. In Esherichia coli and Salmonella, Volume 2. Edited by Neidhardt FC. Washington, D. C: ASM Press; 1996:1903-1999.

38. Liu SL, Hessel A, Sanderson KE: The Xbal-Blnl-Ceul genomic cleavage map of Salmonella typhimurium LT2 determined by double digestion, end labelling, and pulsed-field gel electrophoresis. J Bacterio/ 1993 175(13):4104-4120

39. Neal BL, Brown PK, Reeves PR: Use of Salmonella phage P22 for transduction in Escherichia coli. J Bacteriol 1993, 175(21):7115-7118.

doi:10.1186/1471-2180-14-157

Cite this article as: Bao et al:: Differential efficiency in exogenous DNA acquisition among closely related Salmonella strains: implications in bacterial speciation. BMC Microbiology 2014 14:157.

\section{Submit your next manuscript to BioMed Central and take full advantage of:}

- Convenient online submission

- Thorough peer review

- No space constraints or color figure charges

- Immediate publication on acceptance

- Inclusion in PubMed, CAS, Scopus and Google Scholar

- Research which is freely available for redistribution 